\title{
Transition to Psychiatric Residency: Unique Stresses; Unique Rewards
}

\author{
Catherine A. Belitsky, MD, FRCP(C) \\ University of Toronto, Ontario, Canada \\ Sidney H. Kennedy, MD, FRCP(C) \\ University of Toronto, Ontario, Canada
}

Follow this and additional works at: https://jdc.jefferson.edu/jeffjpsychiatry

Part of the Psychiatry Commons

Let us know how access to this document benefits you

\section{Recommended Citation \\ Belitsky, MD, FRCP(C), Catherine A. and Kennedy, MD, FRCP(C), Sidney H. (1995) "Transition to Psychiatric Residency: Unique Stresses; Unique Rewards," Jefferson Journal of Psychiatry. Vol. 12 : Iss. 2 , Article 8. DOI: https://doi.org/10.29046/JJP.012.2.004 \\ Available at: https://jdc.jefferson.edu/jeffjpsychiatry/vol12/iss2/8}

This Article is brought to you for free and open access by the Jefferson Digital Commons. The Jefferson Digital Commons is a service of Thomas Jefferson University's Center for Teaching and Learning (CTL). The Commons is a showcase for Jefferson books and journals, peer-reviewed scholarly publications, unique historical collections from the University archives, and teaching tools. The Jefferson Digital Commons allows researchers and interested readers anywhere in the world to learn about and keep up to date with Jefferson scholarship. This article has been accepted for inclusion in Jefferson Journal of Psychiatry by an authorized administrator of the Jefferson Digital Commons. For more information, please contact: JeffersonDigitalCommons@jefferson.edu. 


\title{
Transition to Psychiatric Residency: Unique Stresses; Unique Rewards
}

\author{
Catherine A. Belitsky, M.D., FRCP(C) \\ Sidney H. Kennedy, M.D., FRCP(C)
}

\begin{abstract}
An individual's decision to pursue a psychiatric residency following medical school training is shaped by many factors. Beginning residents are often ill prepared for the relative impact that the shift from medical doctor to psychiatric resident entails. This paper reviews the literature regarding demographic and psychological factors relating to recruitment, dynamic and practical issues confronting the beginning resident, and various coping styles adopted. These factors are considered in the context of an inpatient setting where the majority of residents begin their training. Much of the resident response is seen as adaptive and a number of strategies for coping are suggested.
\end{abstract}

\section{INTRODUCTION}

The decision to enter the field of psychiatry is shaped by many factors. Any residency period is a time of great stress, and psychiatric training is no exception. Although common issues are shared in all programs, psychiatry presents its own special challenges.

More than two decades ago, Merklin and Little (1) used the term "Beginning Psychiatry Training Syndrome" to describe a "psychological response occurring the first year of psychiatric training and characterized by transitory neurotic symptoms, psychosomatic disturbances and symptomatic behaviour." They believed that the hospital environment in the first year together with the characteristics of those people who choose psychiatry were the two major factors which influence the development of the syndrome. In our opinion the term "syndrome" should not be used as it implies a pathological or unhealthy response to what is in fact a necessary phase of professional life for any aspiring psychiatrist.

This paper explores the uniqueness of psychiatry as a medical specialty and resultant implications for the beginning resident. Factors related to career choice in psychiatry, issues related to entering psychiatry, and responses to beginning training will be considered.

Catherine A. Belitsky, M.D. is a Fellow in the Women's Mental Health and Mood Disorders Programs at the University of Toronto, where Sidney Kennedy, M.D. is Professor of Psychiatry. 


\section{FACTORS RELATED TO CAREER CHOICE IN PSYCHIATRY}

Why physicians choose psychiatry is the subject of much speculation and little research $(2,3)$. The literature looks at both demographic $(2,4,5)$ and psychological factors $(3,6)$. Obviously the two are interrelated. The choice is certainly a complex one and the future psychiatric resident population is heterogeneous.

\section{A. Demographic Factors}

Students have been studied early in their medical careers, and then reviewed once they have completed the psychiatric component of their medical training. As described in a review article by Eagle and Marcos (2), two groups have been identified. In the first are those who made the decision to become psychiatrists prior to entering medical school. These individuals are less interested in clinical medicine. The second group makes the decision later on during the medical training, often based on the clinical clerkship experience. People in this group are especially interested in the humanities and social sciences, but are also more interested than the first group in the medical curriculum (2-4).

Some have equated this second group with the group that enters primary care medicine, and argue that both training programs are competing for the same group of trainees $(2,4,7)$. Some authors who view primary care and psychiatric students as sharing a similar personality constellation suggest that the decision either way is influenced by socioeconomic variables $(2,7)$.

Others believe that the two groups are basically different. Additionally, 50-75\% of medical students will change their career plans during the course of their training (2). Weissman et al (4) showed that the clerkship rotation in psychiatry is the most important medical school experience which influences students to choose psychiatry.

\section{B. Psychological Factors}

Vaillant (6) hypothesized that troubled physicians may attempt to compensate for unhappiness in childhood by giving others the care that they wished they had received. He found that physicians involved in direct patient care (including psychiatrists) were more likely than non-physician controls and non-patient care physicians to have relatively poor marriages, to heavily use drugs and alcohol, and to seek personal psychotherapy. However, it was only the physicians who were poorly adjusted as children and adolescents who appeared vulnerable to these putative occupational hazards. The findings were inconclusive as the sample size as well as the differences found between physicians and non-physicians were relatively small.

The hypothesis regarding physicians' psychological motivations to practice medicine has been extended more specifically to psychiatrists. Frank and Paris' survey of the literature suggests two main hypotheses regarding the family backgrounds of psychiatrists (3). The "wounded healer" theory suggests that psychiatrists are motivated to resolve personal conflicts through their work. The "family healer" 
theory implies that psychiatrists are motivated to treat family members through their work. Frank and Paris compared psychiatrists with non-psychiatrists. They found some evidence to support the first hypothesis but little to support the second. Interestingly, their results were similar for general psychiatrists as well as psychiatrists identified primarily as psychotherapists. The major drawback to this study involves a low $(<50 \%)$ return rate of their questionnaire. It is also based on adult recollections of childhood which may represent distortion. Nevertheless, it empirically addresses an issue which as mentioned has not been rigorously investigated in literature.

Despite recognition that people now entering psychiatry endorse interests in a diverse range of subspecialties, there has been little written about the characteristics of these subgroups of individuals. Consequently, there is a need for ongoing research and evaluation of the students to keep abreast of this potential demographic and psychological diversity.

\section{ISSUES RELATED TO ENTERING PSYCHIATRY}

The scope of psychiatry is diverse, and the field continues to grow as scientific discoveries emerge. A huge challenge to practitioners involves integrating newer (eg. neuro-scientific) discoveries with existing conceptual models (8). Psychiatrists endorse different theoretical orientations, and this can be overwhelming for the new resident. Residents will also tend to adopt particular psychiatric orientations. Examples include the potential neuroscientists, psychopharmacologists, or more psychodynamically oriented individuals. Clearly the fit between orientation of supervisor and setting, and the resident who is beginning training will be important factors. Book (9) describes a number of stresses which can lead to anxiety during the process of becoming a psychotherapist. These include loss of the "medical model," development of the psychodynamic model and of psychotherapeutic skills, as well as difficulties associated with the treatment process. Although Book associated these stresses with becoming a psychotherapist, many of the issues bear relevance to beginning general psychiatry training and not just psychotherapy. This paper will consider these stresses, and will broaden them to include the context of a general psychiatry inpatient setting as this is where the majority of residents begin their training.

\section{A. Giving Up The "Medical Model"}

In its ideal form, the medical model lends itself to immediate gratification of the physician's narcissistic needs. Examples are readily apparent in surgery, where a troublesome gallbladder is removed and the patient no longer suffers from biliary colic. In these cases the patient is viewed more as a "disease" than as the "diseased." Psychiatry and particularly the field of psychotherapy changes some of this to varying degrees. Patients are people, and not just diseases. This differs somewhat on an inpatient ward where the majority of first year residents begin their training. In this 
setting treatments are often mainly biological, and perhaps this helps ease the transition from the rest of medicine. Nevertheless, even here there is more emphasis on social and family histories.

Entry into psychiatry represents an interesting transition from internship-no more lab coats, no more instruments, and a more humane call schedule. These are for the most part very attractive changes, but they also symbolize a loss. The resident is launched into a new role-identity crisis; from physician to student of psychiatry. The focus moves away from medical problems, and emergencies take on a very different nature. This can be a time for much self questioning and ruminationrumination over career choice and the role the many years of medical training play in psychiatry (9). Unlike aspiring medical or surgical residents, whose medical school training has emphasized teaching in these areas, many incoming psychiatric residents have had little prior experience in psychiatry unless they previously sought electives in this field (5). The resident's past dealings with losses will influence current handling of the loss described.

The self-questioning is only aggravated in a general hospital setting where there can be a feeling of alienation from medical colleagues who have described psychiatry as unscientific, imprecise, ineffective and low in status when compared with other branches of medicine (10,11). A new resident has trouble explaining the differences that exist between psychiatry and more traditional medicine mainly because this is a time when he or she is struggling with these very issues. Book (9) suggests that the psychiatric resident is the recipient of projections from non-psychiatric residents which involve their own feelings of inadequacy in their roles. One cannot overlook the varied non-physician responses to psychiatry. Many do not consider psychiatrists to be "real doctors" and have difficulty understanding the need for medical training, a view which was reflected in responses of medical students in a 1982 survey (11).

\section{B. Development of Psychological Mindedness}

The psychodynamic model or any other predominantly psychotherapeutic model involves developing competence in using the self, and not the laboratory, as the primary instrument of both diagnosis and treatment (9). As competence develops, the resident often turns these new skills inward-this can generate anxiety and increase awareness of his/her own conflicts and areas of difficulty. This is a useful step, but at an early stage, in the unskilled, a blurring of the boundaries between patient and therapist can take place, and can lead to over-identification with the patient $(1,9,12,13)$. The anxiety provoked is not helped by the absence of objective diagnostic measures that can be very reassuring to the hypochondriacal medical student. The boundary in psychiatry between sickness and health is an arbitrary one, and who can confidently define it objectively? Residents may meet patients who present with similar difficulties, similar conflicts and alarmingly similar personal and family histories to their own.

Residents struggle to learn the psychodynamic model which is new and strange at the same time that they are learning and applying a more biological type approach 
on an inpatient unit. The psychodynamic model requires a major shift in focus from the medical model and often occurs without adequate discussion and supervision. Primary supervisors in the first year may not be primarily psychodynamically oriented. This may widen the split between the biological and psychodynamic models, and the resident may experience difficulty developing a conviction that psychodynamic theory and long term psychotherapeutic treatment are meaningful.

\section{Assuming Therapeutic Responsibilities}

Inpatients are among the most difficult patients to treat and are usually treated by the least experienced residents. They are more likely to carry multiple diagnoses on several axes of the DSM classification, and may be regressed and refractory to various treatment options. This can elicit feelings of hopelessness and helplessness in an inexperienced resident. Regarding outpatient psychotherapy, it is often difficult to find appropriate patients for insight oriented work as many of these patients fall to the domain of the experienced therapist. Intolerable countertransference feelings evoked by outpatients can sometimes be viewed by the resident as evidence of his/her own severe psychopathology (9).

There is often a discrepancy between in-patient unit staff expectations and resident skill. All too often staff are naive to the level of knowledge of the beginning resident. As mentioned previously, the psychiatric resident may have had little exposure to this specialty in medical school (5). Unit staff may have much more skill psychiatrically. Chessick (14) comments that "the environment expects the resident to have capacities of empathic understanding and behavioral observation which he has not yet developed." Learning to work with a team and to use the word "we" in decision making may be a new concept for the resident. Shershow (15) commented that "there are obvious transference phenomena within the fabric of staff interaction that may serve as severe stresses to the resident." He believes that the group dynamic on an inpatient ward contributes strongly to regressive behaviors observed in inpatient residents.

As opposed to classic medical treatment, psychiatric treatment emphasizes a "do with" as opposed to a "do for" approach (16). Furthermore, changes in response to psychiatric medication occur comparatively slowly—antidepressant and neuroleptic trials can run for weeks. The timing and approach can become even more frustrating with outpatient psychotherapy. Major movements and changes may not occur until the second year of treatment $(9,12)$. This lack of early therapeutic change is unfortunate as it occurs at a time when the resident's self-esteem and professional gratification are already low. These experiences can be frustrating to a resident whose training was medical more than psychiatric.

"Role shift" refers to the various hats that psychiatrists must wear in treating patients. The most marked shifts in first year have to do with a predominantly biologic approach on the ward, and a dynamic psychotherapeutic approach taught in psychotherapy supervision and seminars. These approaches seem so different, and the many types of therapies offered can be overwhelming. Depending on the 
theoretical frame of reference, there may be profound differences of opinion regarding even basic aspects of patient care $(17,18)$. The type of treatment offered to a patient with a particular symptom, or group of symptoms most often depends on the training background of the treating professional (19). More recently there has been an interest in eclecticism in psychiatry; namely, considering a range of theoretical models in clinical cases and integrating treatment modalities based on the needs of the individual in question $(18,19)$.

At a superficial level psychopharmacological treatment in this setting is a matter of learning the basic aspects of antidepressant, antipsychotic and anxiolytic agents and using them accordingly. However, the prescribing of medication is influenced by transference and countertransference as much as is any other form of treatment. As described by Gabbard (20), dynamically informed pharmacotherapy can significantly enhance the effectiveness of treatment. This is true whether or not formal psychotherapy is part of the treatment. Traditionally, there has been a split between psychotherapy and pharmacotherapy. Despite the competition, research addressing this issue provides evidence for a better outcome with a combined approach than with either psychotherapy or pharmacotherapy alone (21). Clinicians and training residents must therefore learn to practice a challenging dual role (22). They must approach the patient simultaneously as a person who is suffering, and as a diseased central nervous system. Such a process involves balancing the shift between an empathic psychodynamic approach and a more traditional medical model approach.

Residents are often plunged into the role of teaching medical students. Teaching can be satisfying to a new resident in confirming that he/she does have some knowledge to impart. However, although "natural teachers" do exist, for most of us teaching is a skill that evolves over time. There is little if any formal preparation or instruction in how to assume this role. Teaching duties may be experienced as an overwhelming burden for a new resident attempting to assimilate and deal with the transition to psychiatry without adequate support.

\section{RESPONSES TO BEGINNING TRAINING}

How does the resident respond to this vast array of stressors? There are many possibilities. Initially, there is often an increased interest in concomitant medical disorders and their management $(1,9,12,13,16,17)$. An inpatient ward lends itself to these as the resident typically manages both the psychiatric and the physical problems of the patients. Over-identification with patients may lead to eventual decrease in personal involvement. Residents may turn away from psychotherapy as a treatment method and develop and intense biologic interest that was not previously present. Halleck and Woods (12) made an interesting point. "Many residents never seem to reach the potential they initially promised. It is almost as if, in an effort to achieve some sort of equilibrium . . . they say to themselves: 'this is as far as I go and as good as I am going to be. Any further improvement would necessitate anxiety which I am not willing to experience'." Pasnau and Bayley collected psychological data on psychiatry residents before and after one year of training (23). They 
demonstrated a marked increase in depression in all residents. Chessick (14) describes a "flight from anxiety" in which residents constrict themselves in a "narcissistic self limiting fashion." Or, the resident may succumb to what Ornstein (24) describes as dangerous "uncritical eclecticism" resulting in a resident who spreads him/herself too thin and latches onto whatever philosophy is popularconvinced that he/she is safe so long he/she can view this particular viewpoint as factual. A most destructive scenario involves "therapeutic nihilism" in which the resident does not believe in his/her chosen field nor its methods of treatment. Some residents choose to drop out altogether $(9,17)$.

Merklin and Little (1) feel that these responses represent an adaptive response of the new resident to his/her new environment. Obviously it is essential that the resident resolve the anxieties which have been presented. As he/she assimilates, understands and works through these difficulties, he/she will become a better psychiatrist-therapist. It is also true that during the time these experiences are occurring they are difficult to process. It is often only in retrospect that the various factors become more apparent and begin to fall into place.

\section{RECOMMENDATIONS}

For some, the passage of time (experience) with or without personal psychotherapy (1) serve as facilitators in the transition to residency. Where possible additional professional support may be offered. These variables may provide the resident with a framework with which to integrate theoretical and practical experiences and appreciate dynamic factors which often lead to covert frustrations on an inpatient unit.

"Professional support" refers to program related elements which can be helpful in minimizing stress and easing the role transition. Supervision is a significant component of psychiatric residency education. Given the diversity of approaches and treatment modalities (17-19), it is important that residents are exposed to a unifying model-the inpatient team approach composed of a variety of mental health professionals who collaborate in sharing their expertise provides the resident with a broader framework.

Although exposure to many experienced psychiatrists is important, the resident will benefit more fully in his/her development if there is a limited number of close supervisors (25). This focus is helpful in promoting identification with a supervisor who can act as a mentor to foster the resident's own personal professional identity to develop and therefore his/her own particular style and approach. The supervisor can model respect and caring for patients in his/her treatment of the resident (26) and should demonstrate an appreciation of the challenges which are being faced by the beginning resident. Additionally, residents should have the benefit, especially early on, of watching their supervisors as they interview and treat patients $(27,28)$.

Perez et al examined residents' perceptions towards psychotherapy training in a nationwide survey of Canadian residents (26). Of the 50\% who responded there was a positive association between the amount of supervision and residents' evaluation of 
their training. Based on these findings, consideration might be given to allocating more time for psychotherapy supervision, or to supervision in general.

A recent survey by Pate and Wolff (29) involving residents at Baylor College of Medicine in Houston, Texas, corroborates the core factors leading to resident satisfaction with supervision identified in the Perez study. These include: rapport with the resident, teaching ability and fund of knowledge. Careful selection of supervisors by the educational administration can help to enhance the beginning resident's experience. There is also a role for training of supervisors.

Recently a trial of "mentor small groups" was undertaken at the University of Toronto in the Department of Psychiatry during the early months of training. Its goal was to assist first year residents in their transition from general medicine or internship to psychiatry and was based on recommendations by the Resident Stress and Management Subcommittee (30). Groups consisted of five to eight first year residents with more senior residents as group mentors. These were non-therapeutic groups designed to provide a forum for residents to share information, increase awareness of stressors and challenges in first year residency and share coping strategies. At a practical level they were also designed to provide information to residents about the workings of the system including difficulties with emergency call, administration, relationships with staff and peers, and finding a balance between personal and professional responsibilities. Although a formal survey is not available, many residents found this helpful, especially during the early portion of residency until other sources of support were established.

The Chief Resident may also use his/her position as a peer to share personal experiences with new residents (31). Weekly resident lunches organized by the chief resident provide a forum for co-operation amongst peers of various levels of training. Additionally, they may help to diminish peer group competition, and facilitate a supportive, friendly training environment.

In conclusion, the process of entering the psychiatric world and working through the various difficulties encountered presents the new resident with a difficult but rewarding challenge. A clearer understanding of the issues and recognition of the experience as an essential aspect of training may be useful for both resident and supervisor in fostering this important phase of personal and professional development.

\section{REFERENCES}

1. Merklin L, Little RB: Beginning psychiatry training syndrome. Am J Psychiatry 1967; 124:193-197

2. Eagle PF, Marcos LR: Factors in medical students' choice of psychiatry. Am J Psychiatry $1980 ; 137: 423-427$

3. Frank H, Paris J: Psychological factors in the choice of psychiatry as a career. Can J Psychiatry 1989; 32:118-122

4. Weissman SH, Bashook PG: The 1982 first year resident in psychiatry. Am J Psychiatry $1984 ; 141: 1240-1243$ 
5. Chandarana PC, Loncke M, Conlon P: Factors influencing medical students' intentions to choose psychiatry as a career. Can J Psychiatry 1989; 34:425-428

6. Vaillant GE, Sobowale NC, McArthur C: Some psychologic vulnerabilities of physicians. N Engl J Med 1972; 287:372-375

7. Funkenstein DH: Medical Students, Medical Schools and Society During Five Eras: Factors Affecting the Career Choices of Physicians 1958-1976. Cambridge, Mass., Ballinger Publishing Co., 1978

8. Kandel ER: From metapsychology to molecular biology: explorations into the nature of anxiety. Am J Psychiatry 1980; 140:1277-1293

9. Book HE: On maybe becoming a psychotherapist, perhaps. Can Psychiatr Assoc J 1973; 18:487-493

10. Buchanan A, Bhugra D: Attitude of the medical profession to psychiatry. Acta Psychiatr Scand 1992; 85:1-5

11. Yager D, OLamotte K, Nielson A, et al: Medical students' evaluation of psychiatry: a cross-country comparison. Am J Psychiatry 1982; 139: 1003-1009

12. Halleck SL, Woods SM: Emotional problems of psychiatric residents. Psychiatry 1962; 25:339-346

13. Tischler GL: The transition into residency. Am J Psychiatry 1972; 128:1103-1115

14. Chessick RD: How the resident and the supervisor disappoint each other. Am J Psychother $1971 ; 25: 272-283$

15. Shershow JC, Sayodnik I: Regression in the service of residency education. Arch Gen Psychiatry 1976; 33:1266-1270

16. Scanlan JM: Physician to student: The crisis of psychiatric residency training. Am J Psychiatry 1972; 128:1107-1111

17. Yager J: A survival guide for psychiatric residents. Arch Gen Psychiatry 1974; 30:494-499

18. Karasu TB: Psychotherapy and pharmacotherapy: toward an integrative model. Am J Psychiatry 1982; 139:1102-1113

19. Chalfin RM, Altieri J: Supervised treatment of an obsessional patient by a psychiatric resident utilizing psychotherapy and pharmacotherapy. Am J Psychotherapy 199I; XLV: 43-52

20. Gabbard GO: Psychodynamic Psychiatry in Clinical Practice. Washington DC, American Psychiatric Press, 1990

21. Luborsky L, Singer B, Luborsky L: Comparative studies of psychotherapies: is it true that "everybody has won and all must have prizes?" in Evaluation of Psychological Therapies, Behavior Therapies, Drug Therapies, and Their Interaction. Eds, Spitzer RL, Klein DF. Baltimore, Johns Hopkins University Press, 1976, pp 3-22

22. Docherty JP, Marder SR, Van Kammen DP, et al: Psychotherapy and pharmacotherapy: conceptual issues. Am J Psychiatry 1977; 134:529-533

23. Pasnau RO, Bayley SH: Personality changes in the first year of psychiatric residency training. Am J Psychiatry 1971; 128:83-84

24. Ornstein PH: The Sorcerer's Apprentice. Compr Psychiatry 1968; 9:293-315

25. Greben SE, Markson ER, Sadavoy J: Resident and supervisor: an examination of their relationship. Can Psychiatr Assoc J 1973; 18:473-479

26. Perez EL, Krul LE, Kapoor R: The teaching of psychotherapy in Canadian psychiatric residency programs: residents' perceptions. Can J Psychiatry 1984; 29:658-663

27. Hamilton JW: Some aspects of learning, supervision, and identity formation in the psychiatric residency. Psychiatr Quarterly $1971 ; 45: 410-422$ 
28. Rabinowitz CB: Supervision of residents: Teaching must keep pace with knowledge. Academic Psychiatry 1990; 14:142-145

29. Pate LA, Wolff TK: Supervision: the residents' perspective. Academic Psychiatry 1990; $14: 122-128$

30. Hsu K, Belitsky C, Dolan D, et al: Resident Stress and Management Subcommittee (89-90) Report to Post-Graduate Education Committee, Department of Psychiatry, University of Toronto, 1990

31. Grant I, Dorus W, McGlashan T, et al: The chief resident in psychiatry. Arch Gen Psychiatry 1974; 30:503-507 